\title{
Isolation and Structural Characterization of Phytoconstituents from Strobilanthes kunthianus
}

\author{
Geetha Balasubramaniam ${ }^{1,2}$, Mahendran Sekar ${ }^{3, *}$, Subban Ravi ${ }^{4}$, Shrishailappa Badami ${ }^{5}$
}

Geetha Balasubramaniam ${ }^{1,2}$, Mahendran Sekar ${ }^{3, *}$, Subban Ravi $^{4}$, Shrishailappa Badami ${ }^{5}$

'Department of Pharmaceutical Chemistry, Swamy Vivekanandha College of Pharmacy, Elayampalayam, Tiruchengode-637205, Tamilnadu, INDIA

${ }^{2}$ Department of Pharmaceutical Chemistry, JSS College of Pharmacy, JSS Academy of Higher Education and Research, Rocklands, Udhagamandalam - 643001, Nilgiris, Tamilnadu, INDIA.

${ }^{3}$ Department of Pharmaceutical Chemistry, Faculty of Pharmacy and Health Sciences, Universiti Kuala Lumpur Royal College of Medicine Perak, Ipoh - 30450, Perak MALAYSIA.

${ }^{4}$ Department of Chemistry, Karpagam Academy of Higher Education, Coimbatore 640 021, Tamil Nadu, INDIA.

${ }^{5}$ Chaitanya Vikas Yoga \& Nature Cure Centre, Rajatgiri, Dharwad - 580004, Karnataka, INDIA.

\section{Correspondence}

\section{Assoc. Prof. Dr. Mahendran Seka}

Department of Pharmaceutical Chemistry, Faculty of Pharmacy and Health Sciences, Universiti Kuala Lumpur Royal College of Medicine Perak, Ipoh - 30450, Perak, MALAYSIA.

Phone no: (6016) - 3346653;

Fax: (605) - 2536634;

E-mail: mahendransekar@unikl.edu.my

History

- Submission Date: 09-07-2020;

- Review completed: 16-08-2020;

- Accepted Date: 31-08-2020.

DOI : 10.5530/pj.2020.12.220

Article Available online

http://www.phcogj.com/v12/i6s

Copyright

(c) 2020 Phcogj.Com. This is an openaccess article distributed under the term of the Creative Commons Attribution 4.0 International license.

\section{ABSTRACT}

Background: Strobilanthes kunthianus T Anders (Neela kurinji) is well known for its medicinal properties and reported to possess many biological activities. However, so far there is no phytoconstituents are isolated and reported in S. kunthianus. Objective:The present study aimed to isolate and characterize the chemical constituents present in various parts of $S$. kunthianus. Methods: The successive petroleum ether root and stem extracts, chloroform stem extract, macerated and crude methanol flower extracts were subjected to column chromatography for the isolation of constituents. All the isolated compounds were characterized based on their physical and spectral data analysis. Results: Ten compounds were isolated and being reported for the first time from S. kunthianus. Except lupeol (1 and 2), betulin (3), $\alpha$-amyrin (5) and $\beta$-sitosterol (7), other five compounds including of 3,5-bis-(dimethylcarbamoyl)methyl)-4-(11cyclohexylundecyl)-4-heptyl- $\mathrm{N}^{1}, \mathrm{~N}^{1}, \mathrm{~N}^{7}, \mathrm{~N}^{7}$ tetramethylheptanediamide (4), 4-amino-tetrahydro2H-pyran-3,5-diol (6), 2-(2-hydroxyethyl)-3-methyl-4-((E)-3,6-dimethylundec-4-enyl)cyclohexyl propionate (8), flavone glycoside (9) and decahydro-1,1,4a,8-tetramethylphenanthren$2(1 \mathrm{H}, 3 \mathrm{H}, 4 \mathrm{bH})$-one $(\mathbf{1 0})$, isolated from $S$. kunthianus were novel. Conclusion: The novel compounds need to be further investigated for ascertain pharmacological activities which will be useful for further drug development.

Key words: Strobilanthes kunthianus, Neela kurinji, Phytoconstituents, Column chromatography, Flavone glycoside.

\section{INTRODUCTION}

Natural products offer huge structural varieties and up-to-date techniques for isolation, structural characterization, screening and combinatorial preparations have led to renaissance of plant products as sources of new drugs. ${ }^{1-4}$ The importance of plant based drugs, the introduction of medicinal plants in the form of nutraceuticals and dietary supplements are also altering the current trend dominated by synthetic drugs to plant-based drug market. $^{5}$

Strobilanthes kunthianus (S. kunthianus) is a shrub in the grasslands of Western Ghats in India. The Nilgiris, which literally means the blue mountains got its name from the purplish blue flowers of Neela kurinji that blossoms gregariously once in twelve years. ${ }^{6,7} S$. kunthianus is well known for its medicinal properties and reported to possess many biological activities. ${ }^{8}$ Everlyne et al. ${ }^{9}$ studied FT-IR and GC-MS analysis of ethanolic leaves extract of S. kunthianus and reported that it may contains aromatic hydrocarbons, straight chain primary alcohols, fatty acids, alkenes, phenolic compounds, titerpene alcohols and triterpenes, primary aliphatic alcohols and trienoic fatty acids. Prabakaran and Kirutheka ${ }^{10}$ identified ten phytoconstituents based on GC-MS analysis in callus methanolic extract of $S$. kunthianus and studied for antioxidant properties. However, so far there is no phytoconstituents are isolated individually in various plant parts of $S$. kunthianus. Therefore, the present study was aimed to isolate and characterize the phytoconstituents present in various parts of $S$. kunthianus.

\section{MATERIALS AND METHODS}

An electrothermal IA-9200 was used to determine melting points of the isolated compounds. IR spectrum was obtained from Perkin Elmer FTIR 1275X. The EIMS spectrum was obtained from a 5989 B MS spectrometer from Hewlett Packard. A Bruker AM500 FT-NMR spectrometer was used to record ${ }^{1} \mathrm{H}$ NMR and ${ }^{13} \mathrm{C}$ NMR spectra, and TMS was used as an internal standard. Column chromatography was performed using silica gel (60-120 \& 100-200 mesh, Merck).

\section{Collection and authentication}

The whole plant of S. kunthianus was collected from Thalaikuntha region, near Udhagamandalam, Nilgiris District, Tamilnadu, India. The plant was identified and authenticated at Botanical Survey of India, Coimbatore, Tamilnadu, India.

\section{Extraction}

The whole plant was washed thoroughly with water and separated into different parts viz stem, leaves, flowers and roots. These were shade dried and powdered separately using a mechanical blender before extraction.

\section{Successive extraction}

The powdered root and stem of S. kunthianus (500 g) were extracted successively with 2.51 each of

Cite this article: Balasubramaniam G, Sekar M, Ravi S, Badami S. Isolation and Structural Characterization of Phytoconstituents from Strobilanthes kunthianus. Pharmacogn J 2020;12(6)Suppl:1605-11. 
petroleum ether, chloroform, ethyl acetate and methanol in a Soxhlet apparatus separately for $18-20 \mathrm{~h}$. The extracts were concentrated in a rotary evaporator under reduced pressure at $35-40{ }^{\circ} \mathrm{C}$ and stored at $4{ }^{\circ} \mathrm{C}$ in a refrigerator till further use.

\section{Cold maceration}

The powdered leaves and flowers $(250 \mathrm{~g})$ were extracted with $1.5 \mathrm{l}$ of methanol by cold maceration separately by agitation for 7 days and filtered. The mass was squeezed out and again subjected for remaceration for 7 days and filtered off. The combined filtrate was concentrated similarly as stated in successive extraction method.

\section{Crude extraction}

The powdered root, stem, leaves and flowers of S. kunthianus (500 g) were extracted separately with $2.5 \mathrm{l}$ of methanol in a Soxhlet apparatus for $18-20 \mathrm{~h}$. The extracts were concentrated similarly as stated in successive extraction method.

\section{Isolation and characterization of phytoconstituents}

Isolation is a part of natural product research, through which it is possible to separate components. The biologically active ones can be incorporated as ingredients in the modern system of medicine. The column chromatographic technique (adsorption chromatography) is widely used for the separation, isolation and purification of the natural products. The principle involved in this is the adsorption towards the adsorbent packed in the column. By changing the polarity of the mobile phase, the separation was achieved by column chromatography. Characterization of the isolated compounds were carried out by different analytical techniques like IR, NMR and Mass spectroscopy (MS).

\section{Column chromatography of petroleum ether root extract of S. kunthianus}

The petroleum ether root extract ( $6 \mathrm{~g}$ ) was chromatographed over silica gel 60-120 mesh of column length $60 \mathrm{~cm}$ and diameter 3 $\mathrm{cm}$. Elution was carried out with solvents and solvent mixtures of increasing polarities. The fractions were collected in $25 \mathrm{ml}$ portions and monitored on TLC and the fractions showing similar spots were combined. The fractions 143-172 eluted with chloroform:ethyl acetate (80:20) gave a white precipitate which showed two major spots on TLC. Hence, it was subjected for re-column chromatography to isolate the two compounds. The remaining fractions were not worked out because of lower yields. The white precipitate $(3.2 \mathrm{~g})$ obtained from fractions 143-172 was further chromatographed over silica gel 100-200 mesh of column length $50 \mathrm{~cm}$ and diameter $3 \mathrm{~cm}$. Elution was carried out with solvents and solvent mixtures of increasing polarities. The fractions were collected in $10 \mathrm{ml}$ portions and monitored on TLC. The fractions 25-48 eluted with petroleum ether: acetone (90:10) gave a white residue and showed single spot with tailing. Repeated recrystallisation in methanol yielded colorless needle shaped crystals which showed a single spot on TLC with petroleum ether: acetone (85:15). TLC studies were carried out in different solvent systems to prove the homogeneity. It was designated as compound $\mathbf{1}$ (Yield $1.4 \mathrm{~g}, 23.33 \%$ ). The next fraction (49-56) which gave colourless white residue was washed several times with petroleum ether and on recrystallisation in chloroform yielded a colorless compound and its homogeneity was confirmed by TLC studies, designated as compound 3 (Yield $0.31 \mathrm{~g}, 5.17 \%$ ). Compounds $\mathbf{1}$ and $\mathbf{3}$ were subjected to physical and spectral studies for confirming their purity and characterization. The remaining fractions were not worked out because of lower yields.

Column chromatography of petroleum ether stem extract of $S$. kunthianus

The petroleum ether stem extract (5.6 g) was chromatographed over silica gel 100-200 mesh of column length $100 \mathrm{~cm}$ and diameter $1.2 \mathrm{~cm}$. Elution was carried out with solvents and solvent mixtures of increasing polarities. The fractions were collected in $50 \mathrm{ml}$ portions and monitored on TLC and the fractions showing similar spots were combined. The fractions 46-64, on elution with chloroform: ethyl acetate (60:40) yielded a yellow residue $(2.1 \mathrm{~g})$ which showed on TLC single spot with tailing. On repeated recrystallisation with methanol it gave a colorless needle shaped crystalline compound and its homogeneity was proved by TLC studies and designated as compound 2 (Yield $0.9 \mathrm{~g}, 16.07 \%$ ). This compound was subjected to physical and spectral studies for confirming the purity and characterization. The remaining fractions were not worked out because of lesser yields.

\section{Column chromatography of chloroform stem extract of $S$.} kunthianus

The chloroform stem extract ( $2.5 \mathrm{~g})$ was chromatographed over silica gel 100-200 mesh of column length $100 \mathrm{~cm}$ and diameter $1.2 \mathrm{~cm}$. Elution was carried out with solvents and solvent mixtures of increasing polarities. The fractions were collected in $25 \mathrm{ml}$ portions and monitored on TLC and the fractions showing similar spots were combined. The fractions, 25-55 eluted with petroleum ether: chloroform (80:20) gave a light green residue. On repeated washing with acetone, it yielded a colourless residue. The colourless residue was dissolved in minimum quantity of chloroform and filtered off. The filtrate on evaporation yielded a white semisolid compound, which on repeated washing with acetone and recrystallisation with chloroform yielded a colorless residue and its homogeneity was confirmed with various solvent systems by TLC and designated as compound 4 (White semisolid; Melting point $118^{\circ} \mathrm{C}$; Yield $0.016 \mathrm{~g}, 0.64 \%$ ). This compound was subjected to physical and spectral studies for confirming the purity and characterization. The remaining fractions were not worked out because of lesser yields.

\section{Column chromatography of macerated methanol flower extract} of S. kunthianus

The macerated methanol flower extract (6 g) was chromatographed over silica gel 60-120 mesh of column length $50 \mathrm{~cm}$ and diameter $3 \mathrm{~cm}$. Elution was carried out with solvents and solvent mixtures of increasing polarities. The fractions were collected in $50 \mathrm{ml}$ portions and monitored on TLC and the fractions showing similar spots were combined. The fractions 59-76 eluted with chloroform: ethyl acetate (60:40) gave a yellow residue and showed one major spot along with other minor impurities on TLC. Repeated recrystallisation with chloroform: methanol (90:10) gave a colorless compound. The colorless compound showed a single spot in petroleum ether: ethyl acetate (88:12) and was further proved for its homogeneity with different solvent systems by TLC and designated as compound 5 (Yield $0.015 \mathrm{~g}, 0.25 \%$ ).

The fractions 89-95 eluted with ethyl acetate gave a brown residue. On washing with acetone, followed by methanol washing it gave a white crystalline compound. The white crystalline compound which showed a single spot with TLC by using different solvent systems was designated as compound 6 (White crystalline; Melting point $132^{\circ} \mathrm{C}$; Yield 0.012 g, $0.20 \%)$. These compounds were subjected to physical and spectral studies for confirming their purity and characterization. The remaining fractions were not worked out because of lesser yields.

\section{Column chromatography of crude methanol flower extract of S. kunthianus}

The crude methanol flower extract $(50 \mathrm{~g})$ was chromatographed over silica gel 60-120 mesh of column length $60 \mathrm{~cm}$ and diameter 10 $\mathrm{cm}$. Elution was carried out with solvents and solvent mixtures of increasing polarities. The fractions were collected in $100 \mathrm{ml}$ portions and monitored on TLC and the fractions showing similar spots were combined. The fractions 11-30 eluted with petroleum ether: 
chloroform (50:50) gave a colorless residue which on purification with acetone gave a fluffy white precipitate and its homogeneity was checked by TLC in $n$-hexane: ethyl acetate (65:35) and was further confirmed with different solvent systems by TLC. It was designated as compound 7 (Yield $0.012 \mathrm{~g}, 0.02 \%$ ). The fractions (31-50) eluted in chloroform were mixed together, evaporated to a minimal volume and then added acetone. White amorphous sticky residue was obtained. Repeated washing with acetone and recrystallisation with chloroform yielded a colorless precipitate, showed a single spot on TLC in n-hexane: ethyl acetate (50:20) and it was designated as compound $\mathbf{8}$ (Colorless powder; Melting point $87^{\circ} \mathrm{C}$; Yield $\left.0.01 \mathrm{~g}, 0.02 \%\right)$. The fractions $148-189$ eluted with ethyl acetate: methanol $(60: 40)$ gave a sticky brown residue. This was washed several times with methanol and repeatedly recrystallized with water. A reddish brown compound was obtained. Its homogeneity was checked with chloroform: methanol: water (8:2:0.1) and designated as compound 9 (Reddish brown; Melting point $256^{\circ} \mathrm{C}$; Yield 0.025 g, $0.05 \%)$. These compounds were subjected to physical and spectral studies for confirming their purity and characterization. The remaining fractions were not worked out because of lesser yields and mixtures of compounds.

\section{Isolation by solvent-solvent extraction of macerated methanol leaves extract of S. kunthianus}

The macerated methanol leaves extract $(7 \mathrm{~g})$ was fractionated with petroleum ether $(500 \mathrm{ml})$. The petroleum ether layer was separated and evaporated. A colourless semisolid residue was obtained which on repeated washing with acetone and recrystallization with chloroform gave a colourless precipitate. Its homogeneity was checked with various solvent systems by TLC and designated as compound $\mathbf{1 0}$ (Colorless powder; Melting point $136{ }^{\circ} \mathrm{C}$; Yield $0.01 \mathrm{~g}, 0.14 \%$ ). This compound was subjected to physical and spectral studies for confirming its purity and characterization.

\section{Column chromatography of other extracts of S. kunthianus}

Among all the extractions, the compounds were isolated only from successive petroleum ether stem and root extracts, successive chloroform stem extract, macerated leaves and flower extracts and crude methanolic flower extract. Other extracts from successive, maceration and crude extraction methods were subjected to column chromatography but couldn't isolate any compounds.

\section{RESULTS AND DISCUSSION}

Chromatographic separation of root, stem and flower extracts of S. kunthianus afforded nine compounds, five of them $(4,6,8,9$ and 10) being described for the first time (Figure 1). From the spectral data of the compounds isolated from successive petroleum ether root extract were identified as lupeol (1 and 2) and betulin (3). Lupeol (2) was also isolated from petroleum ether stem extract. 3,5-bis(dimethylcarbamoyl)methyl)-4-(11-cyclohexylundecyl)-4-heptyl$\mathrm{N}^{1}, \mathrm{~N}^{1}, \mathrm{~N}^{7}, \mathrm{~N}^{7}$-tetramethylheptanediamide (4) was isolated from chloroform stem extract. a-Amyrin (5) and 4-amino-tetrahydro2H-pyran-3,5-diol (6) were isolated from macerated methanol flower extract. $\beta$-sitosterol (7), 2-(2-hydroxyethyl)-3-methyl-4-((E)3,6-dimethylundec-4-enyl)cyclohexyl propionate (8) and a flavone glycoside (9) were isolated from crude methanol flower extract. Decahydro-1,1,4a,8-tetramethylphenanthren-2(1H,3H,4bH)-one (10) was isolated from macerated methanol leaves extract. The homogeneity of all the isolated compounds were proved by a single spot on TLC using silica gel $\mathrm{G}$ as an adsorbent and solvent mixtures of different polarities as developers. The solvent systems used and the corresponding $R_{f}$ values were given in Table 1 .

\section{Characterization of compounds 1 and 2}

The ${ }^{1} \mathrm{H}$ NMR spectra displayed a one proton multiplet at $\delta 3.20$ is assignable to $\mathrm{H}-3$ on the basis of biogenetic analogy. The ${ }^{1} \mathrm{H} /{ }^{1} \mathrm{H}-\mathrm{COSY}$ experiment exhibited the coupling between $\mathrm{H}-3$ with $\mathrm{H}-2 \alpha$ (1.59 ppm) and $\mathrm{H}-2 \beta(1.30 \mathrm{ppm})$ indicating that the hydroxyl group is at $\mathrm{C}-3$. The seven methyl groups resonated at $\delta 1.70$ (H-30), 1.01 (H-28), 0.95 (H-26), 0.93 (H-23), 0.81 (H-27), $0.77(\mathrm{H}-24)$, and $0.75(\mathrm{H}-25)$. The presence of two doublets at $\delta 4.60$ and 4.70 each integrating for one proton was attributed to methylene group at C-20. The multiplet at $\delta$ 2.40 for one proton is assigned to $\mathrm{H}-18$. The assignments were made based on the HSQC experiments.

The ${ }^{13} \mathrm{C}$ NMR and INEPT experiments showed the presence of 30 carbon atoms consisting of six quaternary carbons, six methine, eleven methylene carbons and seven methyl groups. The signals at $\delta 109.31$ and 150.98 indicates the presence of a $\mathrm{C}=\mathrm{C}$ group out of which one is a quaternary carbon and the other is a carbon of a vinyl methylene group. The signal at $\delta 79.04$ is attributed to C-3. The signals at $\delta 27.95$, $19.31,18.00,16.17,16.05,15.43$ and 15.29 were due to the presence of seven methyl groups in the compound. The other signals in accordance with the proposed structure of the compound which was identified as lupeol (Figure 1).

\section{Characterization of compound 3}

The ${ }^{1} \mathrm{H}$ NMR spectra displayed a one proton multiplet at $\delta 3.19$ is assignable to $\mathrm{H}-3$ on the basis of biogenetic analogy. The six methyl groups resonated at $\delta 1.68(\mathrm{H}-30), 1.02(\mathrm{H}-26), 0.98(\mathrm{H}-23), 0.97(\mathrm{H}-$ 27), $0.82(\mathrm{H}-24)$ and $0.76(\mathrm{H}-25)$. The presence of two doublets at $\delta 4.60$ and 4.70 each integrating for one proton were attributed to methylene group at C-20. The multiplet at $\delta 2.40$ for one proton is assigned to $\mathrm{H}-18$. The pair of doublet signals at $\delta 3.80$ and 3.32 each integrating for one proton was assigned to $\mathrm{H}-28$. The ${ }^{13} \mathrm{C}$ NMR and INEPT experiments showed the presence of 30 carbon atoms consisting of six quaternary carbons, six methine, twelve methylene carbons and six methyl groups. The signals at $\delta 109.68$ and 150.98 indicates the presence of a $\mathrm{C}=\mathrm{C}$ group out of which one is a quaternary carbon and the other is a carbon of a vinyl methylene group. The signal at $\delta 78.98$ is attributed to C-3. The signals at $\delta 27.97,19.07,16.10,15.97,15.35$ and at $\delta 14.75$ were due to the presence of six methyl groups in the compound. The signal at $\delta 60.56$ is due to a hydroxy methylene carbon atom (C-28). The other signals are in accordance with the proposed structure of the compound which was identified as betulin (Figure 1).

\section{Characterization of compound 4}

Compound 4 obtained as a colourless solid, on elemental analysis showed the values C: $71.64, \mathrm{H}: 11.42, \mathrm{~N}: 7.73$ [Calcd. C: $71.82, \mathrm{H}$ : $11.49, \mathrm{~N}: 7.79$ ] had a molecular weight of 718.14 and a molecular formula of $\mathrm{C}_{43} \mathrm{H}_{82} \mathrm{~N}_{4} \mathrm{O}_{4}$. In its ${ }^{1} \mathrm{H}$ NMR it showed a triplet at $\delta 0.93$ (H-19') indicating a methyl group which is adjacent to a methylene group. There is a strong singlet at $\delta 1.29$ indicating the presence of a long chain methylene groups ( $\mathrm{H}-1^{\prime}$ to $\left.\mathrm{H}-18^{\prime}\right)$. The singlets at $\delta 2.10$ and 2.20 indicate the presence of four methylene groups attached to four carbonyl groups. The strong singlet at $\delta 2.70$ for 24 protons shows the presence of eight methyl groups attached to nitrogen atoms. The ${ }^{13} \mathrm{C}$ NMR spectrum showed a signal at $\delta 13.99\left(\mathrm{C}-19^{\prime}\right)$ indicating the presence of only one methyl group. The signal at $\delta 29.55$ supports above interpretations that the compound contains long chain methylene carbon atoms ( $\mathrm{C}-1^{\prime}$ to $\left.\mathrm{C}-18^{\prime \prime}\right)$. The strong signal at $\delta 40.91$ confirms the presence of methyl groups attached to nitrogen atom and all the methyl groups are in the same environment. The above data suggests that the compound may contain four $\mathrm{N}, \mathrm{N}$-dimethyl acetamide groups $\left(-\mathrm{CH}_{2}-\right.$ CO-N-( $\left.\left(\mathrm{CH}_{3}\right)_{2}\right)$ attached to two different methylene groups as shown below. 
Table 1: TLC profile, chemical test and melting point of isolated compounds from S. kunthianus.

\begin{tabular}{|c|c|c|c|c|c|}
\hline $\begin{array}{l}\text { Compound } \\
\text { Number }\end{array}$ & Mobile phase/Solvent system & Solvent ratio & $R_{f}$ value & Qualitative chemical test & Melting point $\left({ }^{\circ} \mathrm{C}\right)$ \\
\hline \multirow{4}{*}{1 and 2} & Chloroform: ethyl acetate & $68: 32$ & 0.57 & \multirow{4}{*}{$\begin{array}{c}\text { Exhibited positive response with anisaldehyde- } \\
\text { sulfuric acid reagent indicating their triterpenoid } \\
\text { nature }\end{array}$} & \multirow{4}{*}{213} \\
\hline & Toluene: ethyl acetate & $82: 18$ & 0.49 & & \\
\hline & Petroleum ether: acetone & $85: 15$ & 0.30 & & \\
\hline & Dichloromethane: methanol & $95: 05$ & 0.65 & & \\
\hline \multirow{4}{*}{3} & Chloroform: ethyl acetate & $68: 32$ & 0.85 & \multirow{4}{*}{$\begin{array}{c}\text { Exhibited positive response with anisaldehyde- } \\
\text { sulfuric acid reagent indicating its triterpenoid } \\
\text { nature }\end{array}$} & \multirow{4}{*}{252} \\
\hline & Toluene: ethyl acetate & $82: 18$ & 0.78 & & \\
\hline & Petroleum ether: acetone & $85: 15$ & 0.62 & & \\
\hline & Dichloromethane: methanol & $95: 05$ & 0.70 & & \\
\hline \multirow{4}{*}{4} & Petroleum ether: ethyl acetate & $90: 10$ & 0.47 & \multirow{4}{*}{ Not performed due to lack of quantity } & \multirow{4}{*}{118} \\
\hline & Chloroform: methanol & 98:02 & 0.69 & & \\
\hline & Petroleum ether: acetone & 95:05 & 0.30 & & \\
\hline & n-hexane: ethyl acetate & $80: 20$ & 0.51 & & \\
\hline \multirow{4}{*}{5} & Petroleum ether: chloroform & $70: 30$ & 0.32 & \multirow{4}{*}{$\begin{array}{l}\text { Exhibited positive response with anisaldehyde- } \\
\text { sulfuric acid reagent indicating its triterpenoid } \\
\text { nature }\end{array}$} & \multirow{4}{*}{180} \\
\hline & n-hexane: acetone & $75: 25$ & 0.71 & & \\
\hline & Petroleum ether: ethyl acetate & $88: 12$ & 0.52 & & \\
\hline & Toluene: ethyl acetate & $60: 40$ & 0.82 & & \\
\hline \multirow{3}{*}{6} & Chloroform: ethyl acetate & $10: 90$ & 0.42 & \multirow{3}{*}{ Not performed due to lack of quantity } & \multirow{3}{*}{132} \\
\hline & Toluene: ethyl acetate & $20: 80$ & 0.61 & & \\
\hline & Petroleum ether: acetone & $65: 35$ & 0.80 & & \\
\hline \multirow{3}{*}{7} & Petroleum ether: chloroform & $60: 40$ & 0.52 & \multirow{3}{*}{$\begin{array}{c}\text { Exhibited positive response with Libermann- } \\
\text { Buchard's and Salkowski tests indicating its } \\
\text { steroidal nature }\end{array}$} & \multirow{3}{*}{138} \\
\hline & Petroleum ether: ethyl acetate & $80: 20$ & 0.74 & & \\
\hline & n-hexane: ethyl acetate & $65: 35$ & 0.47 & & \\
\hline \multirow{3}{*}{8} & Dichloromethane: acetone & $82: 18$ & 0.66 & \multirow{3}{*}{ Not performed due to lack of quantity } & \multirow{3}{*}{87} \\
\hline & n-hexane: ethyl acetate & $50: 20$ & 0.57 & & \\
\hline & Chloroform: ethanol & $90: 10$ & 0.46 & & \\
\hline \multirow{3}{*}{9} & Chloroform: methanol: water & $50: 45: 5$ & 0.72 & \multirow{3}{*}{ Not performed due to lack of quantity } & \multirow{3}{*}{256} \\
\hline & Ethyl acetate: methanol & $70: 30$ & 0.63 & & \\
\hline & Chloroform: methanol: formic acid & $60: 38: 2$ & 0.47 & & \\
\hline \multirow{3}{*}{10} & n-hexane: ethyl acetate & $95: 05$ & 0.52 & \multirow{3}{*}{ Not performed due to lack of quantity } & \multirow{3}{*}{136} \\
\hline & Petroleum ether: chloroform & $60: 40$ & 0.74 & & \\
\hline & Petroleum ether: ethyl acetate & $75: 25$ & 0.64 & & \\
\hline
\end{tabular}

$\left(\mathrm{CH}_{3}\right)_{2} \mathrm{~N}-\mathrm{CO}-\mathrm{CH}_{2}-\mathrm{C}-\left(-\mathrm{CH}_{2}-\mathrm{CO}-\mathrm{N}-\left(\mathrm{CH}_{3}\right)_{2}\right)$

Since all similar groups are in the same environment these groups should be attached to one carbon atom.

\section{$-\mathrm{CH}-\left[\mathrm{C}-\left(-\mathrm{CH}_{2}-\mathrm{CO}-\mathrm{N}-\left(\mathrm{CH}_{3}\right)_{2}\right)_{2}\right]_{2}$}

Two other valencies of this carbon atom have been satisfied by the long chain methylene groups. Further in the DEPT-135 spectra, it showed 12 signals in the positive side for $\mathrm{CH}_{3}$ and $\mathrm{CH}$ carbons and 26 signals in the opposite side for $\mathrm{CH}_{2}$ groups. The Mass spectrum indicates that the base peak at $\mathrm{m} / \mathrm{z} 83.44$ suggests a cyclohexane ring system. After that successive peaks differ by a mass unit of 14 . The $\mathrm{m} / \mathrm{z} 97.00$, $111.29,125.18,139.07,153.00,166.85,180.76,194.70,208.00,222.50$, $236.41,250.40,264.35,278.18,292.15,306.08,320.02,334.93$ and at 348.93 strongly supporting that the compound contains a long chain methylene groups. Based on the above facts the structure was proposed as shown in Figure 1.

\section{Characterization of compound 5}

The ${ }^{1} \mathrm{H}$ NMR spectra exhibited two doublets at $\delta 0.85$ and 0.93 (each $3 \mathrm{H}$, $\mathrm{H}-29$ and $\mathrm{H}-30)$, and six singlets at $\delta 1.25(3 \mathrm{H}, \mathrm{H}-23), 1.16(3 \mathrm{H}, \mathrm{H}-26)$, $0.86(3 \mathrm{H}, \mathrm{H}-27), 0.84(3 \mathrm{H}, \mathrm{H}-28), 0.82(3 \mathrm{H}, \mathrm{H}-25)$ and $0.70(3 \mathrm{H}, \mathrm{H}-24)$ indicating the presence of eight methyl groups in the compound. The multiplet signal at $\delta 5.35(1 \mathrm{H}, \mathrm{H}-12)$ indicates the presence of a double bond wherein one of the carbon is tetrasubstituted. The signal at $\delta 3.52$ $(1 \mathrm{H}, \mathrm{m}, \mathrm{H}-3)$ is characteristic of a proton under hydroxy function is also present in the compound. These facts suggest the presence of a triterpenoid nucleus. The ${ }^{13} \mathrm{C}$ NMR spectrum exhibited 30 signals indicating the presence of 30 carbon atoms and supports the presence of a triterpenoid. The signals at $\delta 121.79$ and 139.79 indicate the presence of one double bond. The signal at $\delta 71.81$ shows the presence of a carbon atom connected to a hydroxy group. The hydroxyl group is placed in the C-3 position for biogenetic considerations. The signals at $29.68,11.96$, $11.94,18.99,21.07,25.39,19.38$ and 24.29 were safely attributed to the methyl groups of the triterpenoid moiety. On comparison of the signals with the known triterpenoids, it matched with the signals of $\alpha$-amyrin (Figure 1).

\section{Characterization of compound 6}

Compound 6 obtained as a white crystalline compound, on elemental analysis showed the values C: $45.16, \mathrm{H}: 8.39, \mathrm{~N}: 10.61$ [Calcd. C: 45.10 , $\mathrm{H}: 8.33, \mathrm{~N}: 10.52$ ] had a molecular weight of 133.15 and a molecular formula of $\mathrm{C}_{5} \mathrm{H}_{11} \mathrm{NO}_{3}$. The ${ }^{1} \mathrm{H}$ NMR spectrum showed two doublet integrating for two protons each at $\delta 3.88(\mathrm{H}-2 \alpha, \mathrm{H}-6 \alpha)$, and at 3.61 $(\mathrm{H}-2 \beta, \mathrm{H}-6 \beta)$. It also exhibited a complex multiplet of signals centered at $\delta 3.69$ for three protons $(\mathrm{H}-3, \mathrm{H}-4$ and $\mathrm{H}-5)$. The downfield signal of the H-4 may be due to the intramolecular hydrogen bonding of the amino and hydroxyl group protons with each other. In the ${ }^{1} \mathrm{H} /{ }^{1} \mathrm{H}$ COSY spectrum the $\mathrm{H}-2 \alpha$ and $\mathrm{H}-6 \alpha$ protons showed cross peaks with $\mathrm{H}-2 \beta$ and $\mathrm{H}-6 \beta$ respectively showing that they mutually couple with each other. Cross peaks were observed between the $\mathrm{H}-3, \mathrm{H}-4$ and $\mathrm{H}-5$ protons with the H-2 and H-6 protons showing that they couple with each other and thereby suggesting that they are in adjacent positions. The ${ }^{13} \mathrm{C}$ NMR spectrum exhibited only three signals indicating a highly symmetrical environment in the molecule. The signals appeared at $\delta$ 


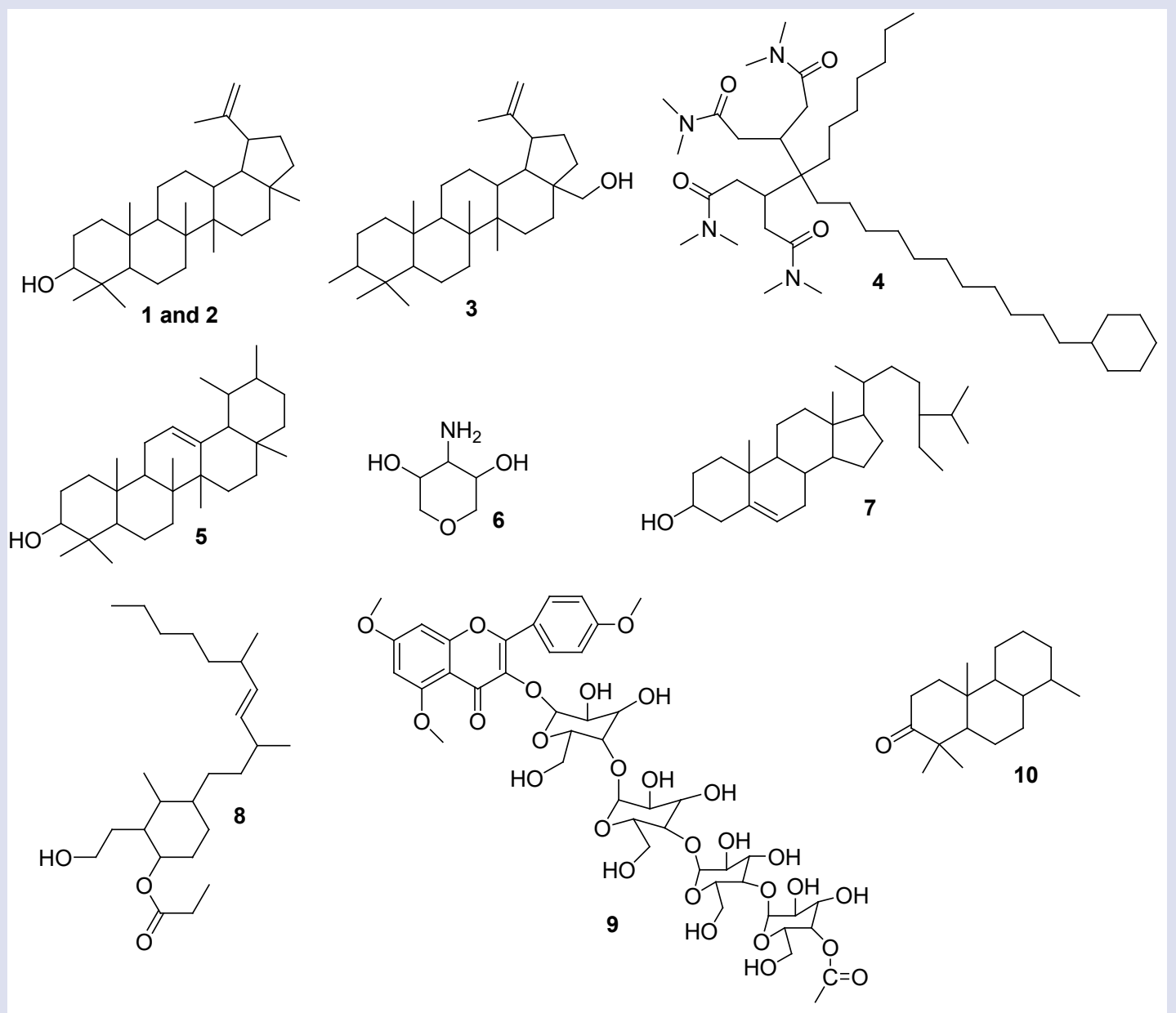

Figure 1: Chemical structure of isolated compounds from S. kunthianus.

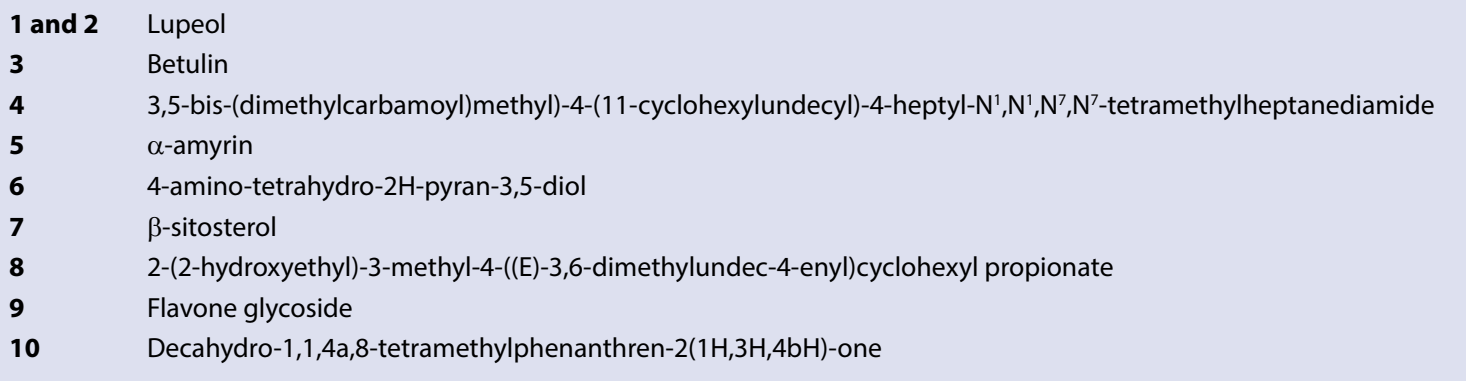

63.30, 69.39 and 70.98 suggesting that all the carbon atoms are under hetero atoms $(\mathrm{N}$ or $\mathrm{O})$. The intensity of the peak at $\delta 63.30$ is more than the other two peaks indicating the presence of more than one carbon atom in that environment. Further the DEPT 135 spectrum of this compound showed that only one peak at $\delta 63.30$ (methylene carbons C-2 and C-6) is in the positive side and the other two signals at $\delta 69.39$ $(\mathrm{C}-4)$ and at $\delta 70.98$ (C-3 and C-5) are in the negative side. Based on the above facts the structure was proposed as shown in Figure 1.

\section{Characterization of compound 7}

The ${ }^{1} \mathrm{H}$ NMR spectrum displayed signals for two tertiary methyl groups at $\delta 0.70(\mathrm{~s}, 3 \mathrm{H}, \mathrm{C}-18)$ and $\delta 1.01(\mathrm{~s}, 3 \mathrm{H}, \mathrm{C}-19$,). Three secondary methyl groups at $\delta 0.94(\mathrm{~d}, 3 \mathrm{H}, \mathrm{Me}-21), 0.82(\mathrm{~d}, 3 \mathrm{H}, \mathrm{Me}-26), 0.85(\mathrm{~d}, 3 \mathrm{H}, \mathrm{Me}-$ 27) and a primary methyl group at $\delta 0.88(\mathrm{t}, 3 \mathrm{H}, \mathrm{Me}-29)$. The broad multiplet signal at $\delta 5.35(1 \mathrm{H}, \mathrm{m})$ was attributed to $\mathrm{H}-6$ and the hydroxy methine proton signal at $\delta 3.52(1 \mathrm{H}, \mathrm{m})$ was attributed to $\mathrm{H}-3$ for biogenetic considerations. ${ }^{1} \mathrm{H}$ NMR, $\delta$ (ppm): 0.70 (s, 3H, C-18). 0.82 $(\mathrm{d}, 3 \mathrm{H}, \mathrm{J}=6.4 \mathrm{~Hz}, \mathrm{Me}-26), 0.85(\mathrm{~d}, 3 \mathrm{H}, \mathrm{J}=6.4 \mathrm{~Hz}, \mathrm{Me}-27), 0.88(\mathrm{t}, 3 \mathrm{H}$, $\mathrm{J}=7.5 \mathrm{~Hz}, \mathrm{Me}-29), 0.94$ (d, 3H, J = 6.5 Hz, Me-21), 1.01 (s, 3H, C-19), $3.52(\mathrm{~m}, 1 \mathrm{H}, \mathrm{C}-3), 5.35$ ( $\mathrm{m}, 1 \mathrm{H}, \mathrm{C}-6)$. The ${ }^{1} \mathrm{H}$ NMR and ${ }^{13} \mathrm{C}$ NMR values are in agreement with $\beta$-sitosterol (Figure 1).

\section{Characterization of compound 8}

Compound 8 obtained as a colourless precipitate, on elemental analysis showed the values C: 76.18, H: 11.02 [Calcd. C: 76.09, H: 11.75] had a molecular weight of 394.63 and a molecular formula of $\mathrm{C}_{25} \mathrm{H}_{46} \mathrm{O}_{3}$. The ${ }^{1} \mathrm{H}$ NMR exhibits a multiplet at $\delta 5.3(\mathrm{H}-11)$ for one proton indicating that one of the carbon atoms is tetra substituted. The ${ }^{13} \mathrm{C}$ NMR spectra of the compound 8 exhibits two signals at $\delta 118.21$ (C-11) and 142.58 $(\mathrm{C}-12)$ in the unsaturated region of the spectrum indicating that there is only one double bond in the compound. In ${ }^{13} \mathrm{C}$ NMR it exhibits signals at $\delta 75.21(\mathrm{C}-3)$ and $61.19(\mathrm{C}-24)$ indicating two carbon atoms attached to oxygen function. The former signal at $\delta 75.21$ appears to be a signal of a methine carbon which is esterified. Accordingly, the 
carbonyl carbon appears at $\delta$ 173.76. Consistently, its ${ }^{1} \mathrm{H}$ NMR signal appears as a multiplet at downfield region $\delta 4.0(\mathrm{H}-3)$ for one proton. The latter signal at $\delta 61.19$ appears to be of a hydroxy methyl signal. In the ${ }^{1} \mathrm{H}$ NMR spectrum corresponding methylene protons appears in the downfield region at $\delta 4.8(\mathrm{~m}, 1 \mathrm{H}, \mathrm{H}-24)$ and $4.5(\mathrm{~m}, 1 \mathrm{H}, \mathrm{H}-24)$ each for one proton. This signal can go down only if the hydroxyl group is hydrogen bonded with the carbonyl group. Due to hydrogen bonding it will reduce the electron density in the C-24 carbon and the signals go downfield. This suggests that the carbonyl group and the hydroxy methyl group are nearby each other. There is no signal in between $\delta$ 40 and 60 in the ${ }^{13} \mathrm{C}$ NMR. The presence of a methyl group in the C-5 position makes the carbon $\mathrm{C}-4$ electron rich and the signal moves towards up field region and appears at $\delta 39.98$. For similar reasons the long hydrocarbon chain which contains the double bond is connected to C-6. Since there is no other functional group is found in the compound the methyl group at $\mathrm{C}-12$ makes it tetra substituted. To avoid the signals of C-10 and C-13 to go downfield region a methyl group was placed at C-9. The DEPT-135 spectra showed 11 signals in the positive side for $\mathrm{CH}_{3}$ and $\mathrm{CH}$ carbons and 12 signals in the opposite side for $\mathrm{CH}_{2}$ groups. All the other signals are in accordance with the structure. The mass spectrum also confirms the long chain hydro carbon. Based on the above facts the structure was proposed as shown in Figure 1.

\section{Characterization of compound 9}

Compound 9 obtained as a reddish brown solid, on elemental analysis showed the values C: $53.27, \mathrm{H}: 5.73$ [Calcd. C: $53.27, \mathrm{H}: 5.65$ ] had a molecular weight of 856.26 and a molecular formula of $\mathrm{C}_{38} \mathrm{H}_{48} \mathrm{O}_{22}$. The ${ }^{1} \mathrm{H}$ NMR spectrum exhibited a triplet at $\delta 1.10$ and a methylene signal at $\delta 1.80$ showing the presence of the aliphatic short chain system. The strong signal at $\delta 2.50$ for nine protons suggests the presence of three methoxy groups. The signals at $\delta 7.20\left(1 \mathrm{H}, \mathrm{s}, \mathrm{H}-5^{\prime}\right), 6.41$ and $6.34(\mathrm{~d}$, $\left.2 \mathrm{H}, \mathrm{H}-2, \mathrm{H}-3^{\prime}\right), 6.20(1 \mathrm{H}, \mathrm{s}, \mathrm{H}-6)$ and at $\delta 6.07(1 \mathrm{H}, \mathrm{s}, \mathrm{H}-8)$ supports the presence of the flavanoid moiety. The signals at $\delta 5.20(1 \mathrm{H})$ and 4.70 $(2 \mathrm{H})$ showed the presence of three anomeric protons. The complex of signals between $\delta 3.29$ and 3.89 exhibits the presence of three glucose units. The ${ }^{13} \mathrm{C}$ NMR spectrum exhibited two signals at $\delta 182.32$ and 175.15 showing the presence of two carbonyl groups. The signals at $\delta$ 156.84 (C-5), 159.57 (for two carbon atoms, C-7, C-9), 161.80 (C-4') and $164.47(\mathrm{C}-2)$ indicating the presence of phenolic carbon atoms and the signals at $115.51\left(\mathrm{C}^{\prime} 3^{\prime}, \mathrm{C}^{\prime} 5^{\prime}\right), 120.88$ (C-2', C-6'), 128.05 (C-1'), 102.58 (C-10), 97.55(C-8) and 95.20 (C-6) suggests the presence of a flavanoid nucleus. The signals at $\delta 102.31,99.98$ and 94.93 were characteristic of anomeric carbon atoms. In addition to this a couple of signals between $\delta 60.66$ and 80.55 indicate the presence of three glycosidic moieties. The signals at $\delta 53.31$ (for two carbons) and 59.16 suggest the presence of three methoxy groups. One of the carbonyl group at $\delta 182.32$ may be assigned to the flavanoid nucleus. Apart from this the signals at $\delta 33.10$ along with unassigned carbonyl signal indicates the presence of acetate moiety. The downfield signal at $\delta 128.04$ shows that C- 3 is substituted with oxygen function. It is probable that the glucoside moieties are joined one after another at C-3. Absence of phenolic protons in the ${ }^{1} \mathrm{H}$ NMR spectrum and presence of methoxy protons indicate that all the phenolic hydroxyl groups are substituted with methoxy groups. In the DEPT- 135 spectra showed 25 signals in the positive side for $\mathrm{CH}_{3}$ and $\mathrm{CH}$ carbons and 3 signals in the opposite side for $\mathrm{CH}_{2}$ groups. The normal ${ }^{13} \mathrm{C}$-NMR spectra showed signals for 38 carbons and suggested that 10 quartnary carbon atoms are present in the compound. Since all the positions are satisfied with protons and methoxy groups, the probability of the attachment of the acetic acid group may not be possible in the flavanoid nucleus. It can be safely placed at the end of the glucosidic moiety. Hence, the structure was proposed as shown in Figure 1.

\section{Characterization of compound 10}

Compound 10 obtained as a colorless solid, on elemental analysis showed the values C: $82.48, \mathrm{H}: 11.61$ [Calcd. C: $82.38, \mathrm{H}: 11.52$ ] had a molecular weight of 856.26 and a molecular formula of $\mathrm{C}_{38} \mathrm{H}_{48} \mathrm{O}_{22}$. The compound 10 in its ${ }^{1} \mathrm{H}$ NMR spectrum exhibits a peak at $\delta 1.20$ characteristic of the secondary and tertiary methyl groups. The strong singlet at $\delta 1.60$ is characteristic of methylene protons in a ring system. The signal at $\delta 2.20$ is due to the methylene groups attached to a carbonyl group. The ${ }^{13} \mathrm{C}$ NMR spectrum exhibits signals for 18 carbon atoms and a peak at $\delta 205$ indicates the presence of a carbonyl group. The HSQC spectra showed the presence of four methyl groups, seven methylene groups, four methane groups and three quartnery carbon atoms.

The signal at $\delta 30.00$ showed the presence of many methylene groups inside a ring system. The mass spectrum a molecular ion peak at 262.173 (calculated 262.23) indicating a molecular formula of $\mathrm{C}_{18} \mathrm{H}_{30} \mathrm{O}$. Based on the above facts the structure was proposed as shown in Figure 1.

\section{CONCLUSION}

All these compounds herein described were isolated for the first time from S. kunthianus. Except lupeol (1 and 2), betulin (3), a-amyrin (5) and $\beta$-sitosterol (7), other five compounds $(4,6,8,9$ and 10) isolated from $S$. kunthianus were novel, revealed that $S$. kunthianus extracts containing novel phytoconstituents which may be responsible for its biological properties. In future, in-vitro and in-vivo studies are warranted to conduct on these isolated compounds to identify its safety and efficacy.

\section{CONFLICTS OF INTEREST}

No potential conflicts of interest was reported by the authors.

\section{REFERENCES}

1. Clardy J, Walsh C. Lessons from natural molecules. Nature. 2004;432(7019):829 37.

2. Corcoran O, Spraul M. LC-NMR-MS in drug discovery. Drug Dis Today. 2003;8:24-631.

3. Ganesan A. Recent developments in combinatorial organic synthesis. Drug Dis Today. 2002;7:47-55

4. Steinbeck C. Recent developments in automated structure elucidation of natural products. Nat Prod Rep. 2004;21(4):512-8.

5. Cardellina $\mathrm{JH}$. Challenges and opportunities confronting the botanical dietary supplement industry. J Nat Prod. 2002;65(7):1073-84.

6. Balasubramaniam G, Sekar M, Badami S. Pharmacognostical, physicochemical and phytochemical evaluation of Strobilanthes kunthianus (Acanthaceae) Pharmacogn J. 2020;12(4):731-41

7. Sharma MV, Kuriakose G, Shivanna KR. Reproductive strategies of Strobilanthes kunthianus, an endemic, semelparous species in southern Western Ghats, India. 2008. Botanical J Linnean Soc. 2008;157:155-63.

8. Balasubramaniam G, Sekar M, Varadarajan M, Badami S. Antioxidant and hepatoprotective activities of Strobilanthes kunthianus against carbon tetrachloride-induced hepatotoxicity in Rats. Pharmacogn J. 2020;12(5):114351.

9. Everlyne IM, Sangilimuthu AY, Darsini DTP. Spectral analyses of the bioactive compounds present in the ethanolic leaf extract of Strobilanthes kunthiana (Nees) T. Anderson ex. Benth. Adv Biores. 2015;6(3):65-71.

10. Prabakaran R, Kirutheka E. GCMS, phytochemicals and antioxidant activities of in vitro callus extracts of Strobilanthes kunthiana (Nees) T. Anderson ex Benth: An endemic plant of Acanthaceae. Brazilian J Biol Sci. 2018;5(10):359-72. 


\section{GRAPHICAL ABSTRACT}

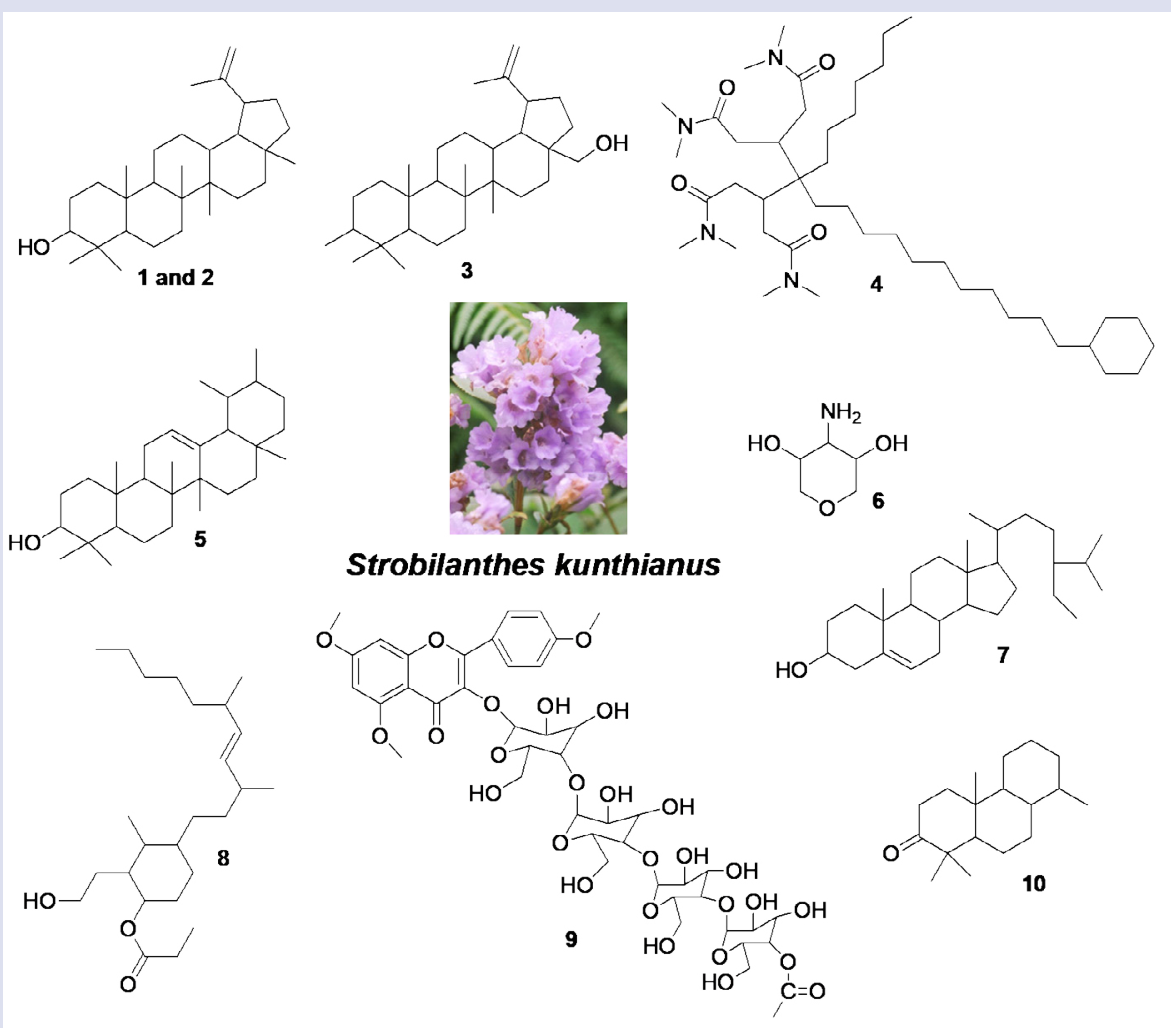

\section{ABOUT AUTHORS}

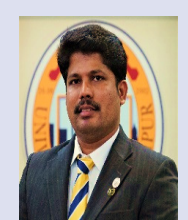

Mahendran Sekar is currently working as an Associate Professor in Department of Pharmaceutical Chemistry, Faculty of Pharmacy and Health Sciences, Universiti Kuala Lumpur Royal College of Medicine Perak, Ipoh, Perak, Malaysia. His research is mainly in the field of drug discovery and development of natural products. His research interest is isolation of active constituents from medicinal plants and study about its biological properties.

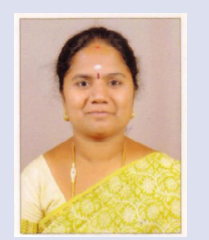

Geetha Balasubramaniam completed her PhD in 2012 at JSS College of Pharmacy, JSS Academy of Higher Education and Research, Udhagamandalam, Tamilnadu, India. She is currently working as a Professor in the Department of Pharmaceutical Chemistry, Swamy Vivekanandha College of Pharmacy, Tamilnadu, India. Her research interest is isolation of active constituents from medicinal plants and study about its biological properties.

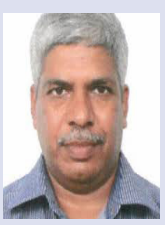

Subban Ravi is currently working as a Professor and Head, Department of Chemistry, Karpagam Academy of Higher Education, Coimbatore, Tamilnadu, India. His research interest is mainly in the field of synthesis, characterization and biological activities of organic compounds. He also interested in isolation and structural characterization of active constituents from medicinal plants.

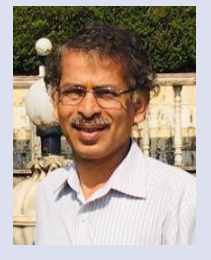

Shrishailappa Badami is currently a proprietor of Chaitanya Vikas Yoga \& Nature Cure Centre, Dharwad, Karnataka, India. His research is mainly in the field of drug discovery and development of natural products. His research interest is isolation of active constituents from medicinal plants and study about its biological properties. At present he is active in manufacturing of herbal products and made it available commercially in the local market.

Cite this article: Balasubramaniam G, Sekar M, Ravi S, Badami S. Isolation and Structural Characterization of Phytoconstituents from Strobilanthes kunthianus. Pharmacogn J. 2020;12(6)Suppl:1605-11. 